\title{
MAPEAMENTO DA SENSIBILIDADE EROSIVA NA BACIA DO RIO SAHY, MUNICÍPIO DE MANGARATIBA (RJ)
}

Maria Luciene da Silva Lima ${ }^{1}$, Débora Rodrigues Barbosa $^{2}$, Renata Ribeiro de Oliveira ${ }^{2}$ (1 - Pontifícia Universidade Católica do Rio de Janeiro, Mestre em geografia, marialucienelima@gmail.com, 2 - Universidade Estácio de Sá, Docente, deborarod@gmail.com, profa.renata.geografia@gmail.com)

Resumo: O estudo propõe avaliar áreas sensíveis aos processos erosivos existentes na bacia hidrográfica do Rio Sahy, buscando compreender seus processos de uso e ocupação, na avaliação de áreas sensíveis às atividades erosivas na análise de riscos. O desenvolvimento do estudo consistiu em etapas de levantamento bibliográfico sobre a área de estudo e fundamentação teórica, análise e seleção de dados secundários georreferenciados (vetoriais e rasters) e tabulares, os quais utilizou-se de técnicas de geoprocessamento com o uso de Sistema de Informação Geográfica (SIG) para avaliação final de mapa síntese na análise as áreas sensíveis. A pesquisa em análise integrada resulta na reflexão sobre as dinâmicas históricas e coletivas de uso e ocupação e cenários atuais das áreas estudadas. O planejamento dos espaços, depende desse conhecimento para gerenciamento de contextos vulneráveis e áreas de risco, os quais normalmente se dão sob múltiplos usos, podendo ser identificados na atualidade como vulnerabilidades para a população local de modo que se possa pensar em sustentabilidades locais a partir da análise das transformações das paisagens dos sistemas socioecológicos em decorrências de tais processos.

Palavras - chave: Geoprocessamento, Análise integrada, Risco

\section{SENSITIVITY MAPPING EROSION IN SAHY BASIN, MANGARATIBA COUNTY}

Abstract:The study proposes to estimate sensitive areas to existing erosive processes in the Sahy basin, trying to understand its use and occupation processes, assessment of sensitive areas to erosive activities in risk analysis. The development of the study consisted of literature steps on the field of study and theoretical foundation, analysis and selection of georeferenced information (vector and raster) and tabular, which was used geoprocessing techniques using

\footnotetext{
Artigo recebido para publicação em 20 de Novembro de 2016
} Artigo aprovado para publicação em 01 de Junho de 2017 


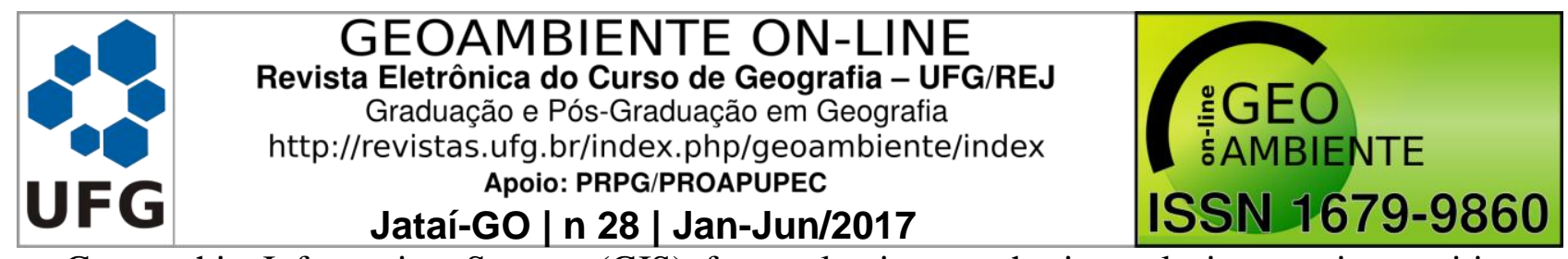

Geographic Information System (GIS) for evaluation synthesis analysis map in sensitive areas. Research on integrated analysis results in reflection on the historical and collective dynamics of use and occupation and current scenarios of the areas studied. The planning of spaces, depends on this knowledge for managing vulnerable contexts and areas of risk, which usually occur in multiple uses and can be identified today as vulnerabilities to the local population so that they can think sustainably from the analysis of the transformations of the landscape of socioecological systems in derivations of such processes.

Keywords: Geoprocessing, Integrated Analysis, Risk

\section{SENSIBILITE CARTOGRAPHIE EN ÉROSIFS SAHY BASSIN, MANGARATIBA DE MUNICIPALITÉ (RJ)}

Résumé: L'étude propose d'évaluer les zones sensibles aux processus érosifs existants dans le bassin de la rivière Sahy, essayant de comprendre ses processus d'utilisation et d'occupation. L'objetive est d'évalue des zones sensibles aux activités érosives dans la technique de l'analyse des risques. Le développement de l'étude se compose d'analyse de la littérature sur le domaine d'études, l'analyse et la sélection des données géo-référencées secondaires (vectorielles et matricielles) et tabulaire, qui a été utilisé des techniques de géotraitement à l'aide du système d'information géographique (SIG) pour l'évaluation finale carte d'analyse dans les zones sensibles. La recherche sur les analyse intégrés expose les dynamiques historiques et collectives d'utilisation et de l'occupation et les scénarios actuels des zones étudiées. La planification des espaces, dépend de cette connaissance pour la gestion des contextes et des zones de risque vulnérables, qui se produisent habituellement dans de multiples usages et peut être identifié aujourd'hui comme des vulnérabilités à la population locale. Ceci est important pour permettre penser à sustainabilities locaux à partir de la analyse des transformations du paysage des systèmes socio-écologiques dans les dérivations de ces processus.

Mots clefs: Géotraitement, Analyse Intégrée, Risque

\section{Introdução}

A partir das dinâmicas históricas e coletivas de uso e ocupação das terras, as resultantes socioecológicas podem ser percebidas nas paisagens como heranças de diferentes usos. As transformações ambientais nas últimas décadas são intensas, tendo como um marco o final do século XVIII, a partir do desenvolvimento da indústria e mecanização da 
agricultura, na busca pelo aumento da produtividade. Sem racionalidade para se preservar os recursos naturais, o emprego de produtos químicos marcou um tempo com relaçãoà preservação dos recursos naturais e com a saúde humana, complexificando e fragilizando cada vez mais as interações humanas com o ambiente.

Não fugindo a esse contexto, a paisagem fluminense e seus entornos, está inserida e conectada com áreas de remanescente florestal da Mata Atlântica, bioma protegido pela Constituição Federal de 1988. Nesse ambiente, há transformações perturbadoras frente aos processos de crescimento econômico das áreas urbanas e periurbanas, como abertura de novas vias, projetos de revitalização de espaços urbanos, crescimento imobiliários, instalação de grandes empreendimentos costeiros e terrestres entre tantas outras questões econômicas e políticas.

Nesse contexto, a Costa Verde conhecida como área de potencial turístico pelas belezas naturais impressas pela Serra do Mar e patrimônio histórico, tem recebido a implantação da indústria de construção naval entre outras atividades econômicas, as quais trazem à região modificações ambientais, sociais e econômicas notáveis nas últimas décadas. Em Mangaratiba (RJ), o cenário tem sido de degradação da paisagem e recursos florestais para seleção de áreas de uso alternativo do solo, a exemplo do que ocorre no entorno do Rio Sahy.Na região, os últimos anos apresentaram a instalação de empreendimentos de grande porte como, obras licenciadas como faixa de servidão de gasoduto e ocupação crescente de empreendimentos imobiliários localizados as margens do rio Sahy, captação de água na bacia hidrográfica, etc. As transformações paisagísticas e ambientais têm fragilizado o meio, gerando problemas relacionados ao lançamento de resíduos sólidos e líquidos nos corpos hídricos, desmatamento, revolvimento dos horizontes superficiais do solo, bem como queimadas e comprometimento do sistema ambiental da bacia hidrográfica. Por todas essas características da região, entende-se a importância da conservação da bacia hidrográfica do rio Sahy para manutenção da biodiversidade dos ecossistemas locais e condições adequadas de habitação para a população local.

Para se entender melhor a dinâmica de transformação dessas paisagens, é fundamental avaliar as interações geográficas, políticas, sociais, econômicas, culturais e históricas, de forma integrada e sistêmica. Dessa maneira, a bacia hidrográfica, como unidade territorial, possui uma importante função como sistema socioecológico, apresentando-se como um sistema funcional e de fundamental importância na mensuração de indicadores geomorfológicos para análise da sustentabilidade ambiental. 


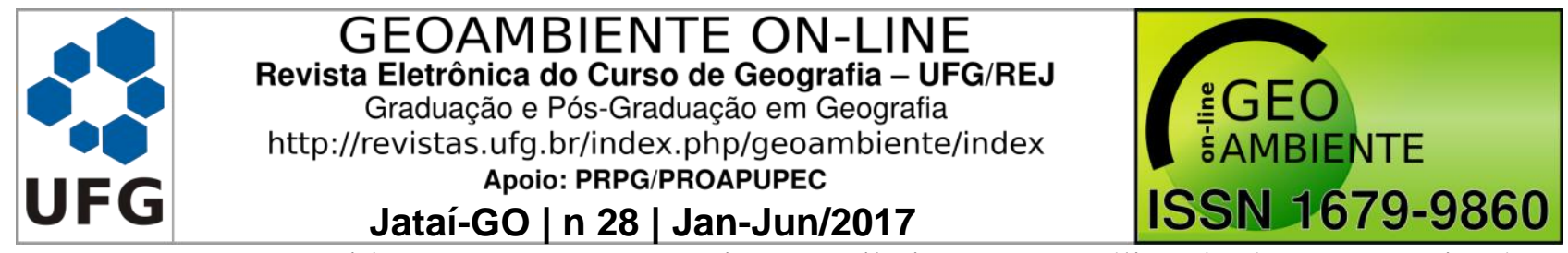

Nesse sentido, o tema proposto visa contribuir para a análise de áreas potencias à ocorrência de processos erosivos na Bacia do Rio Sahy, pretendendo reconhecer os limites geográficos da bacia hidrográfica e dinâmicas de uso e ocupação das terras para subsidiar o mapeamento e diagnóstico das áreas sensíveis a processos erosivos.

\section{Procedimentos Metodológicos}

Materiais e métodos

O desenvolvimento do estudo consistiu nas seguintes etapas: levantamento bibliográfico; análise e seleção dos dados secundários georreferenciados; dois trabalhos de campo exploratório executados nos meses de julho e setembro de 2015; e sistematização dos dados para gerar a análise integrada nas áreas sensíveis à erosão.

São fundamentais como materiais de apoio bases cartográficas, imagens de satélite e modelo de elevação da superfície na leitura da paisagem estudada. Portanto, foram consultadas as cartas topográficas de Itaguaí (SF-23-Z-A-VI-3) e Mangaratiba (SF-23-Z-A-V4) em escala 1:50.000, como apoio aos trabalhos de campo e produção das bases cartográficas (hidrografia, rede viária,áreas urbanas, limites municipais), além das imagens de satélite Landsat 8, cena 217/76 (com data de 10-05-2015), e a obtenção de Modelo Digital de Elevação (ASTER GDEM ${ }^{1}$ ), Folhas S23W044, S23W045 e S24W045, com resolução espacial de 30m, para análise de superfícies e geração dos mapas de declividade e altimetria.

A sistematização de dados espaciais mapeados, foi organizadaemgeodatabase (banco de dados ESRI).

O material adquirido foi submetido a processos de padronização das referências espaciais, utilizando-se projeção UTM para o fuso 23 Sul, e Datum SIRGAS 2000,com o uso do software ArcGIS v. 10.3.

\section{Área de Estudo: A Bacia do rio Sahy}

Ao afirmar que os processos de ocupação humana são contextualizados em extensões espaciais a partir da disponibilidade de água e terreno, Solórzano (2015), afirma que as bacias hidrográficas são de fundamental importância na análise espacial, para metodologias de leitura da paisagem. Nesse contexto, também considera-se de suma importância os crescentes processos de ocupação, em função dos anéis suburbanos, em torno da metrópole do Rio de Janeiro (Rua, 2003). Fatores esses que colocam a região estuda nesse cenário de expansão

\footnotetext{
${ }^{1}$ Dado matricial que representa o relevo, adquirido pelo site de distribuição ASTER GDEM (http://www.jspacesystems.or.jp/ersdac/GDEM/E/4.html)
} 


\section{GEOAMBIENTE ON-LINE Revista Eletrônica do Curso de Geografia - UFG/REJ \\ Graduação e Pós-Graduação em Geografia \\ http://revistas.ufg.br/index.php/geoambiente/index Apoio: PRPG/PROAPUPEC

urbana, diríamos em ritmo acelerado, e por essa razão justifica-se a escolha da bacia do rio Sahy como área de estudo.

A unidade espacial de análise compreende $6,5 \%$ do território municipal do município de Mangaratiba e abrange aos distritos de Praia Grande e São João Marcos. A bacia hidrográfica pertence à Região Costa Verde do Estado do Rio de Janeiro (RJ), e apresenta aproximadamente $23 \mathrm{~km}^{2}$ de área territorial, encontrando-se no contexto da Bacia do Guandu, região hidrográfica Costeira do Atlântico Sul.

O rio Sahy percorre cerca de 6,52 $\mathrm{km}$ até sua foz na praia do Sahy, e sua rede de drenagem deságua no Oceano Atlântico (Figura 1).

Figura 1 - Localização da Área de estudo

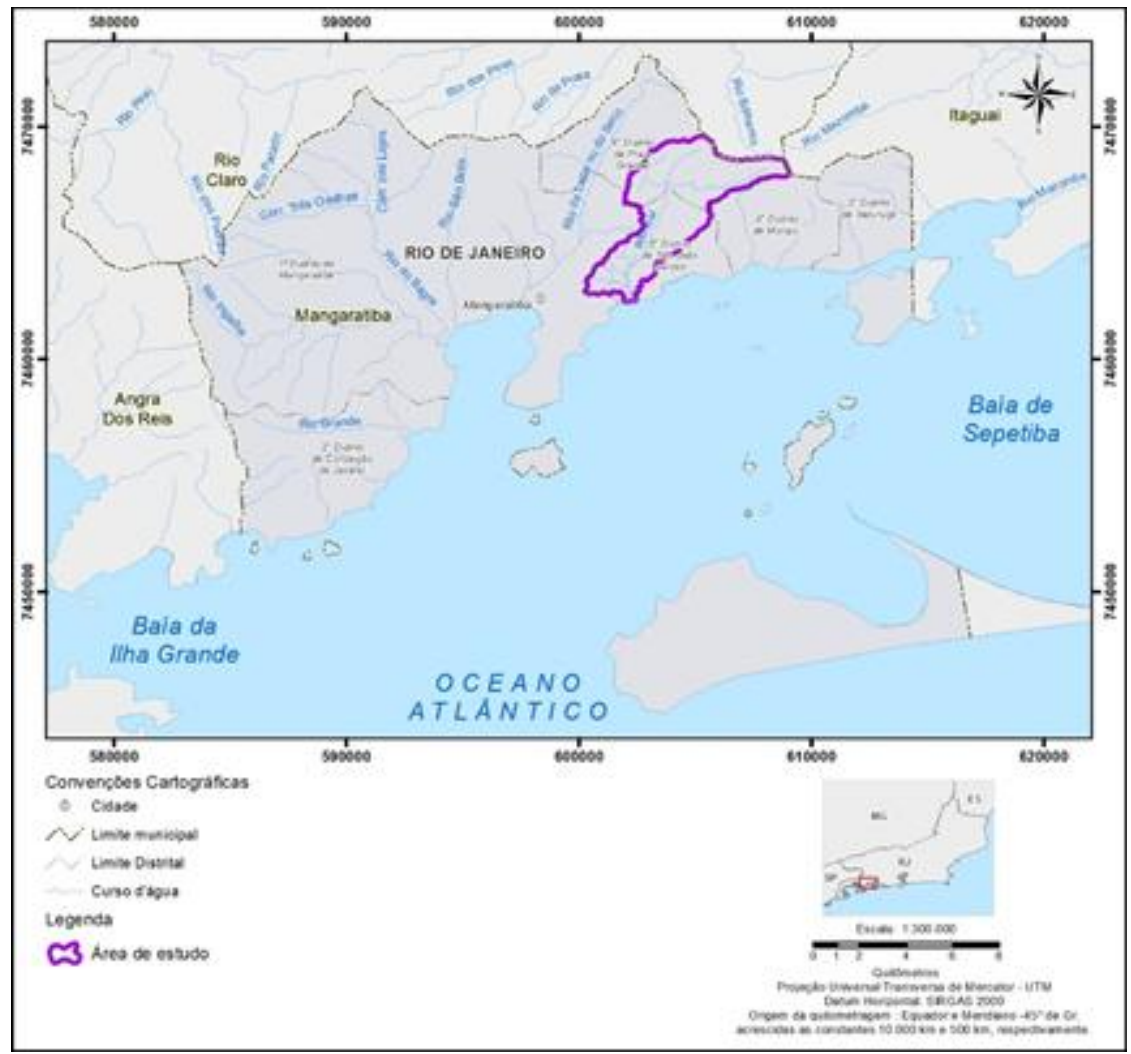

Fonte: Base Contínua, Escala 1:250.000 - IBGE, 2010; Malha Municipal do IBGE 2010; Plano Diretor de Desenvolvimento Sustentável de Mangaratiba (Lei N. ${ }^{\circ}$ 544, de 10 de Outubro de 2006).

Para delimitação da área de estudo utilizou-se o Modelo Digital de Elevação Sensor ASTER (ASTER GDEM), projetado para UTM 23S SIRGAS 2000 e utilizado para gerar análise de hidrológica da bacia do rio Sahy, resultando na delimitação da área de estudo, com o uso da extensão Spatial Analyst do ArcGIS 10.3. Após obtenção dos limites da bacia, foi feito refinamento mais detalhado, utilizando-se ortofotos com resolução espacial de $1 \mathrm{~m}$, 
imagens cedidas pelo INEA ano de 2013. Além de ter subsidiado dados de altimetria de declividade da área de estudo. Dados que apoiaram na compartimentação da bacia em alto curso, médio curso e baixo curso.

A base cartográfica, utilizou-se de dados secundários em escala 1:250.000, adaptado para a escala de 1:100.000, disponibilizados em base de dados públicas do IBGE. Os dados foram manipulados em etapas de padronização das projeções (UTM 23S SIRGAS 2000) e atualizações cartográficas a partir das ortofotos do ano de 2013 (INEA), além de consulta aos dados disponibilizados pelo Plano Diretor de Mangaratiba.

\section{Seleção das variáveis para geração da análise integrada}

O tema de declividade foi produzido a partir do MDE ASTERGDEM, utilizando a ferramenta surface a partir da extensão Spatial Analyst, com o uso do software ArcGIS 10.3. A escolha dessa variável, se deu pela possibilidade de se considerar que níveis superiores a $3^{\circ}$ de declividade, propiciam processos erosivos na paisagem (Jorge \& Guerra, 2013).

Para o mapeamento de uso e cobertura da terra, utilizou-se procedimentos de segmentação com o algoritmo Mean Shift software ArcGIS 10.3, no qual classifica-se a imagem em probabilidades máximas de um conjunto de bandas em formato raster, e gera-se um novo arquivo raster classificado. Logo após a segmentação analisou-se as semelhanças e agrupamentos, e associações através das áreas de treinamento para definição das classes de uso e cobertura.

Foram incorporadas na análise integrada, dois tipos de Áreas de Preservação Permanente (APP) na área de estudo: APP de hidrografia e declividade. Para as delimitações, foram considerados os critérios da legislação vigente (Brasil, Lei 12.651/2012).

As APPs de hidrografia, foram mapeadas a partir da base cartográfica atualizada para escala de 1:50.000. Para geração das APP's de declividade, o raster dessa superfície foi reclassificado e feita a álgebra de mapas selecionando as áreas $\geq 45^{\circ}$, $\operatorname{logo}$ depois transformadas em poligonais.

O mapeamento de solos consistiu nos dados secundáriosdisponibilizados pelo Indicadores Ambientais do Estado do Rio de Janeiro, em escala 1:100.000 (2010), e consulta ao Sistema Brasileiro de Classificação de Solos - SiBCS (2013).

A litologia apresentada, consistiu nos dados secundários elaborados a partir dos relatórios e mapas do Projeto Carta Geológica do Estado do Rio de Janeiro, em escala 
1:50.000, realizado pelo Departamento de Recursos Minerais - DRM/RJ, além da bibliografia existente sobre a geologia do Estado

\section{Análise Integrada: Mapeamento e Análise de áreas sensíveis}

A análise de sensibilidade é um importante instrumento para a compreensão de mudanças e dinâmica evolutiva dos sistemas ambientais. Através dela, é possível avaliar a estabilidade e resiliência dos sistemas, distúrbios e tempo de reação (Christofoletti, 1999), através de mínimas ações ou variações de mudanças externas.

Para Schumm (1991 apud Christofoletti, 1999), a sensibilidade é a tendência que um sistema possui em responder às mudanças externas, de modo que se um sistema for sensível e estiver próximo de um começo de provável alteração ele responderá a uma mudança externa. Dessa maneira, a análise ganha relevância quanto a identificação de potencial ocorrência de eventos geomorfológicos, em particular dos ambientais.

Nesse sentido, a avaliação de áreas sensíveis aos eventos de erosão na bacia, apresentam relevância para estudos ambientais e podem contribuir para o conhecimento de vulnerabilidades e áreas de riscos locais.

As variáveis selecionadas para a análise de áreas com maior pertinência aos eventos de erosão dos solos correspondem as camadas: Declividade, Uso e ocupação das terras, Áreas de Preservação Permanente, Solos e Geologia.

Cada variável foi reclassificada qualitativamente, de modo a dar pesos de acordo com a característica física dos elementos estudados. Atribuiu-se valores baixos para as características que não representam significativas atividades para erosão dos solos e valores mais altos para características que podem favorecer a dinâmica de atividades erosivas. Tal avaliação se deu de acordo com a literatura consultada e reconhecimento de trabalho de campo.

Os valores variam de 0 a 1 na análise multicritério, conforme apresentado na tabela 1 .

A combinação das variáveis, resultam de operadores booleanos, onde foram integrados os dados geográficos discretos representados pelas variáveis supracitadas na tabela1. A álgebra da combinação dessas camadas resultou no mapa síntese, o qual permite a avaliação das áreas sensíveis (Ferreira, 2014). 
Tabela 1 - Padronização das variáveis para determinação das áreas sensíveis à erosão

\begin{tabular}{|c|c|c|c|c|c|c|c|c|c|}
\hline \multicolumn{2}{|c|}{ Declividade } & \multicolumn{2}{|c|}{ Uso e cobertura da terra } & \multicolumn{2}{|c|}{ APP } & \multicolumn{2}{|c|}{ Solos } & \multicolumn{2}{|c|}{ Geologia } \\
\hline Classe $\left({ }^{\circ}\right)$ & Peso & Classe & Peso & Classe & Peso & Classe & Peso & Classe & Peso \\
\hline $0-10$ & 0,1 & $\begin{array}{l}\text { Afloramento, Água, } \\
\text { cordão arenoso, áreas } \\
\text { antropizadas }\end{array}$ & 0 & $\begin{array}{l}\text { APP de } \\
\text { hidrografia }\end{array}$ & 1 & ESPODOSSOLO & 0,15 & $\begin{array}{l}\text { Unidades } \\
\text { Quaternárias }\end{array}$ & 1 \\
\hline $10-20$ & 0,15 & Floresta & 0,1 & $\begin{array}{l}\text { APP de } \\
\text { declividade }\end{array}$ & 0 & CAMBISSOLO & 0,2 & $\begin{array}{l}\text { Unidades } \\
\text { Pre- } \\
\text { Cambianas }\end{array}$ & 0 \\
\hline $20-30$ & 0,2 & Vegetação arbórea & 0,15 & & & NEOSSOLO & 0,25 & & \\
\hline $30-45$ & 0,25 & Agricultura & 0,35 & & & LATOSSOLO & 0,4 & & \\
\hline$>45$ & 0,3 & Pastagem & 0,4 & & & & & & \\
\hline & 1 & & 1 & & 1 & & 1 & & 1 \\
\hline
\end{tabular}

Fonte: organizado por Maria Luciene da Silva Lima.

Os critérios de decisão espacial, foram construídos a partir das resultantes das camadas ponderadas, de uma combinação simples, com o objetivo de responder a algumas perguntas espaciais que poderiam representar maior aptidão para ocorrência de atividades erosivas. Segue um exemplo que consistiu na análise combinatória:

SE

Declividade $>45^{\circ}$

AND

Classes de uso e cobertura da terra sem cobertura florestal

AND

Presença de APP de hidrografia

AND

Solos com pouco desenvolvimentos pedogenéticos

AND

Litologia quaternária

ENTÃO

Maior probabilidade de processos erosivos

Logo foram definidas classes que combinam mais ou menos dos fatores relacionados a análise proposta.

\section{Resultados e discussão}

O espaço geográfico concebe os diferentes arranjos espaciais ou formas assumidas pelos processos naturais ou humanizados na superfície do planeta. Suas abordagens podem ser de diferentes maneiras, revelando as abordagens empíricas da disciplina geográfica, a qual busca em sua origem o entendimento e a diferenciação dos lugares. 


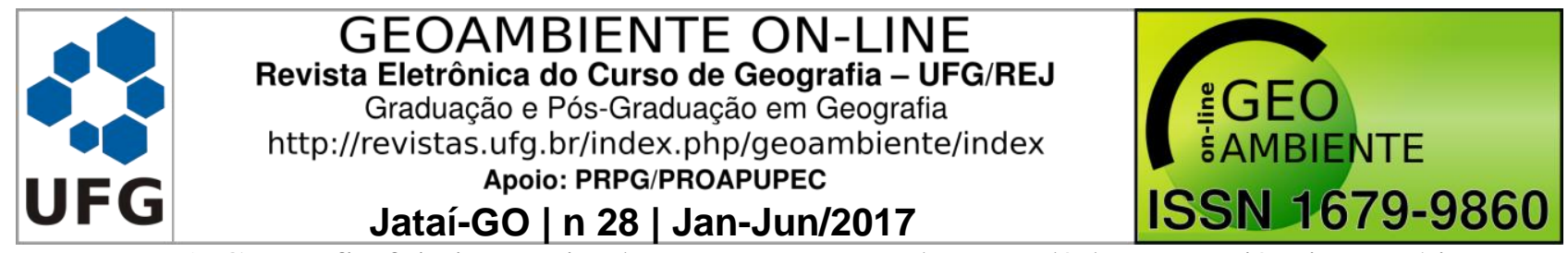

A Geografia foi sistematizada com a proposta de entendê-la como ciência empírica, a partir da observação dos fenômenos e como distribuem-se nas matrizes espaciais.

Alexander von Humboldt, formulou suas próprias ideias sobre o espaço, como sendo a contemplação da universalidade das coisas, numa interação com os seres materiais que coexistem na Terra onde "a impressão do todo, mais do que qualquer outra coisa, cativava a sua mente" (Wulf, 2016, p.90). Dessa maneira, caberia ao estudo geográfico reconhecer a unidade de pesquisa em sua imensa variedade dos fenômenos, e avaliar de forma intuitiva através das observações a constância dos fenômenos em suas variações, propondo o empirismo raciocinado, isto é, a intuição a partir das observações (Moraes, 2007).

Sob essa ótica, buscou-se entender o sistema hidrográfico do rio Sahy de forma holística, a partir das interações sociais, atividades econômicas e culturais existentes, jurisdição e sistemas ecológicos presentes. Portanto, uma avaliação dos sistemas socioecológicos $^{2}$ (Glaser, 2006).

Nesse contexto, ressalta-se a importância de se conhecer os processos culturais, de produção e reprodução social, os quais resultam na transformação da paisagem em diferentes escalas e bases da sociedade.

O espaço como um produto social, é fruto das relações sociais de produção e reprodução biológica, também da força de trabalho e das relações que constituem uma lógica societária e que pode ser refletido por várias dimensões: físico natural, físico material e humana (Lefebvre, 2006). Sob essa ótica, as práticas espaciais pela conexão de fluxos de mercadorias veem sendo modificadas, embora mantendo uma forte relação da vida social com a natureza. Segundo Mattos (2003), uma nova forma de uso do espaço, se apresenta a partir da mercantilização da natureza com o uso de sistemas técnicos que configuram um novo espaço pelas atuais práticas sociais. A autora destaca a urbanização rápida, fazendo com que o espaço de encontro passasse a ser o do mercado de trabalho.

De acordo Barbosa, Oliveira e Silva (2013), o cenário paisagístico do entorno do Rio Sahy representa rica biodiversidade e suas áreas verdes e litorâneas formando ambientes naturais sensíveis que vem sofrendo com a intervenção da sociedade e promovendo degradação ambiental dos recursos naturais.

\footnotetext{
${ }^{2} \mathrm{O}$ conceito de sistemas socioecológicos nos remete a análise do espaço no qual podemos assim afirmar que são complexas as questões pertinentes aos atores envolvidos. Proposta que consiste na análise integrada das relações sociais e ecológicas das sociedades com base nas questões sociais, políticas e econômicas. Pode-se entender esses sistemas a partir de regras internas e do entorno desses sistemas complexos e integrados por diferentes escalas temporais, institucionais e espaciais.
} 


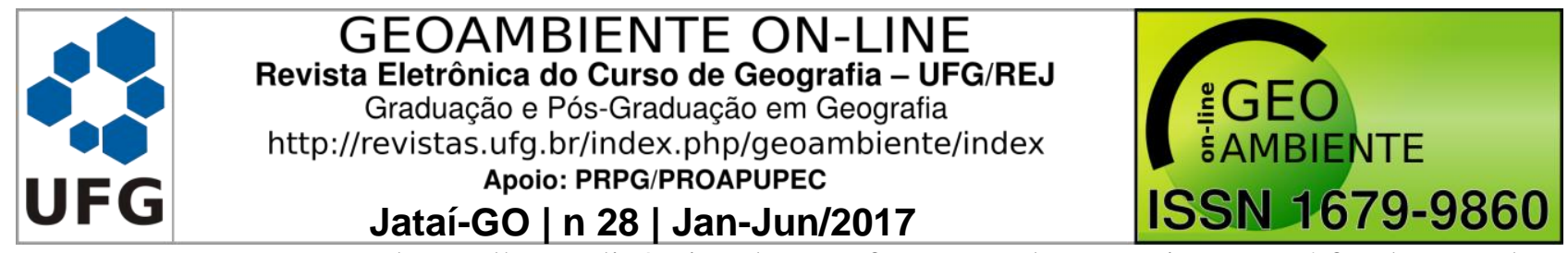

Para se entender melhor a dinâmica de transformação dessas paisagens, é fundamental avaliar as interações geográficas, políticas, sociais, econômicas, culturais e históricas, de forma integrada e sistêmica. Nesse contexto, a bacia hidrográfica como unidade territorial, possui uma importante função como sistema socioecológico, se apresentando como um sistema funcional e de fundamental importância na mensuração de indicadores geomorfológicos para análise da sustentabilidade ambiental.

O município de Mangaratiba possui uma identidade territorial atual, muito diferente de seu período de colonização. Foram diversos conflitos que conduziram as terras mangaratibenses por diferentes ciclos econômicos. Com isso, as paisagens de Mangaratiba carregam a memória da riqueza colonial pretérita, em meio às ruínas e vegetação modificada pelos anos de usos intensificados pelas atividades produtivas da época. Embora, nos dias de hoje, a região apresente exuberância natural pelos abundantes remanescentes de mata atlântica, seu espaço foi muito usado e modificado ao longo dos séculos a partir da chegada da corte imperial no litoral do Rio de Janeiro.

O período do século XVIII retratou uma fase importante na história do município, pois foi um momento em que a trajetória econômica da região expandia-se na vida dos habitantes da Villa de Nossa Senhora da Guia de Mangaratiba ${ }^{3}$. Na localidade, intensas transformações marcavam um redesenho nas relações internas e externas à vila como também a formação espacial da região, a partir de reformas modernistas praticadas pelo comando político do marquês de pombal e também descoberta do ouro em Minas Gerais, motivo principal para a inovação econômica da época.

No início do século XIX, há registros em relação ao aumento do território com o cultivo de terras devolutas, período em que os principais rendimentos dos aldeados era o afloramento das terras, caracterizando novas dimensões espaciais e relações de poder na região. As tensões em relação às disputas por terra, por parte de diferentes grupos, e também a concentração dos colonos desenvolvendo suas atividades na região onde hoje é a sede municipal acontecida com rapidez. Bondim (2014), em seus escritos históricos sobre os conflitos nesse período, relata que existia, a marca de uma nova identidade, não apenas pela população existente, mas também pelo desenvolvimento de atividades econômicas de grande porte com o objetivo de "desenvolver em Mangaratiba uma política urbanizadora de base

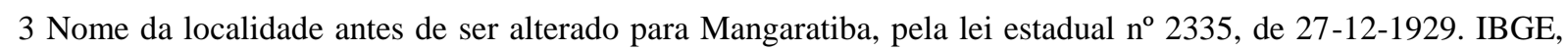
Cidades - Mangaratiba. Disponível em: <http://cidades.ibge.gov.br/xtras/perfil.php?codmun=330260> 27 jun 2016. 
eclesiástica, como também marcava o aumento da presença de brancos no local e dos conflitos na região, relacionados à posse de terras e ao governo sobre os aldeados" (p.19)

Em alguns ensaios sobre a luta de classes e conquista pela terra, Guimarães (1989) em suas análises sobre diferenças, questões agrária e camponesa, comentou sobre o latifúndio cafeeiro na província fluminense e relata que "Pelos meados do século passado, já haviam juntado àqueles dois centros outras áreas pioneiras, com importância semelhante, dentro da região fluminense; e quando se afirmou pouco depois que o "Vale" sustentava o orçamento do Império" (p. 85).

Esse cenário demonstrava um bom desenvolvimento econômico, onde o café penetrava cada vez mais nos grandes centros do mundo, fazendo com que na década de 60 do século XX, estivéssemos exportando em média quase três milhões de sacas (Guimarães, 1989).

Após diferentes períodos históricos de dinamismo e riqueza, declínio de diferentes ciclos econômicos e processos de industrialização na busca pelo crescimento econômico regional e local, Mangaratiba foi perdendo importância no cenário econômico do país. Muitas áreas foram abandonadas como o próprio porto de Mangaratiba, e grandes solares, armazéns, o teatro, existentes no Saco e na Praia do Sahy (Bondim, 2015).

Uma nova espacialidade deu-se no município de Mangaratiba após tantas lutas, diferentes ciclos econômicos nos quais, a paisagem da região sofria modificações constantes em prol dos diferentes usos e também a população residente. Paulatinamente, os bananais foram surgindo e se espalhando pelas serras da região substituindo os espaços abertos pelos cortes de lenha. Logo, a banana ganhou destaque na economia de Mangaratiba, movimentando grande carregamentos que chegavam às paradas de trem, levados por tropas de burros, carroças e barcas. Bondim (2015, p.5), destaca que "Os trens que circulavam pelo município, apelidados por "Macaquinhos", possuíam vagões só para o transporte de peixe, lenha, carvão e, principalmente, para a grande produção de banana."

A organização espacial atual do município de Mangaratiba herda profundas transformações do espaço, visto que a circulação para escoamento de mercadoria, ao longo dos séculos, tem sido intensa, atraindo interesses políticos e econômicos importantes para o Brasil principalmente no período colonial. Em sua paisagem, a memória da riqueza em meio as ruinas e vegetação modificada pelos anos de usos diversos e intensos.

\footnotetext{
${ }^{4}$ A expressão o "Vale" referia-se ao vale do Sahy, região onde localizava-se muitas propriedades da aristocrata família dos Breves, considerado o "rei do café" por meados do século XIX.
} 
No que concerne a essa valorização espacial, a partir da demanda imobiliária, destacase a urbanização rápida no município de Mangaratiba (Tabela 2). Tais processosmarcam uma atualidade que têm se dado no município em função dos anéis suburbanos, em torno da metrópole do Rio de Janeiro aumentando mosaicos paisagísticos de adensamentos urbanos em função de um processo de urbanização diluído em meio a projetos imobiliários à espera de valorização (Rua, 2003).

Tabela 2- Demografia do Estado do Rio de Janeiro

\begin{tabular}{|c|c|c|c|c|c|c|c|}
\hline Município & $\begin{array}{c}\text { População } \\
\text { residente - } \\
2000\end{array}$ & $\begin{array}{c}\text { População } \\
\text { residente - } \\
2014\end{array}$ & Urbana & $\begin{array}{c}\text { Urbana na } \\
\text { sede } \\
\text { municipal }\end{array}$ & Rural & $\begin{array}{c}\text { Área toral } \\
\left(\mathrm{km}^{2}\right)\end{array}$ & $\begin{array}{c}\text { Densidade } \\
\text { demográfica } \\
(\text { hab./km² }\end{array}$ \\
\hline Mangaratiba* & 24.901 & 36.456 & 32.120 & 14.419 & 4.336 & 353 & 103 \\
\hline
\end{tabular}

Fonte: IBGE Cidades - IBGE, censo 2010.

*População estimada em $2014=40.008$ habitantes/ Estimativas da população residente com data de referência $1^{\circ}$ de julho de 204 publicada no Diário Oficial da União em 28/08/2014.

Essas mudanças no espaço de Mangaratiba, podem ser claramente observados na planície da bacia do rio Sahy, onde o dinamismo relativo ao espaço geográfico tem se intensificado,e está diretamente ligado a um padrão espacial de ocupação enfatizado pelas dimensões econômicas - relações produtivas entre classes sociais e capital-trabalho- e também uso do solo na utilização dos recursos da região.

A avaliação dos indicadores das superfícies de erosão e validação dos resultados das análises através de mapas síntese (Figura 2) são representadas áreas com pertinência ao evento físico de processos erosivos apontado áreas com maiores potenciais.

Os dados analisados demonstram cinco níveis na escala de índice de sensibilidade para as áreas mapeadas. As áreas de ocupação e índices de sensibilidade são demonstradas no mapa das áreas com maior potencial a atividades erosivas, como resultado da análise integrada obtida pelo cruzamento dos dados secundários e validação pelas observações das atividades de campo.

$\mathrm{Na}$ abrangência da bacia, vale destacar os canais fluviais e suas margens como áreas sensíveis, tendo em vista que são feições de morfologia de encostas côncavas, cuja características são áreas de depósitos sedimentares e convergentes com o sistema de drenagem, áreas que apresentam uma sensibilidade moderada a eventos erosivos. Assim como no alto curso da bacia, que apresenta significativas porções de áreas com sensibilidade moderada (Figuras 3 A e B), devido à ausência de cobertura vegetal e locais indicadores de 


\begin{tabular}{|c|c|c|}
\hline UF & $\begin{array}{c}\text { GEOAMBIENTE ON-LINE } \\
\text { Revista Eletrônica do Curso de Geografia - UFG/REJ } \\
\text { Graduação e Pós-Graduacăo em Geografia } \\
\text { http://revistas.ufg.br/index.php/geoambiente/index } \\
\text { Apoio: PRPG/PROAPUPEC } \\
\text { Jataí-GO | n 28 | Jan-Jun/2017 }\end{array}$ & $\begin{array}{l}\text { :GEO } \\
\text { ISSN } 1679-9860\end{array}$ \\
\hline
\end{tabular}

processos erosivos, observando proporções de desflorestamento,que podem favorecer para o dinamismo de atividades erosivas, fatores ambientais que indicam áreas sensíveis.

Figura 2-Mapa das áreas com maior potencial a atividades erosivas

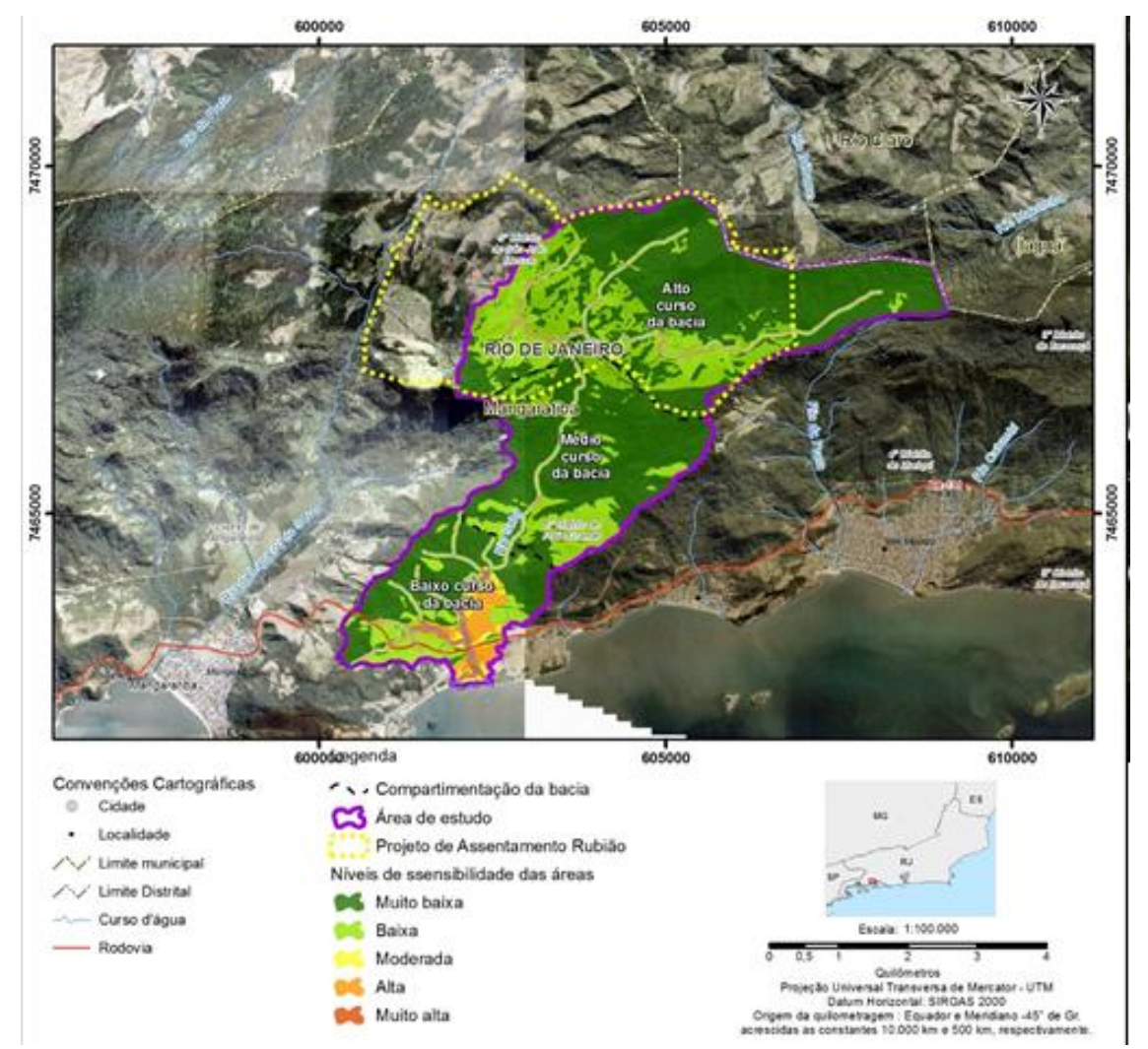

Fonte: Base Contínua, Escala 1:250.000, adaptada para 1:100.000 - IBGE, 2010; Malha Municipal do IBGE 2010 .

Figura 3- Processos erosivos no alto curso da bacia

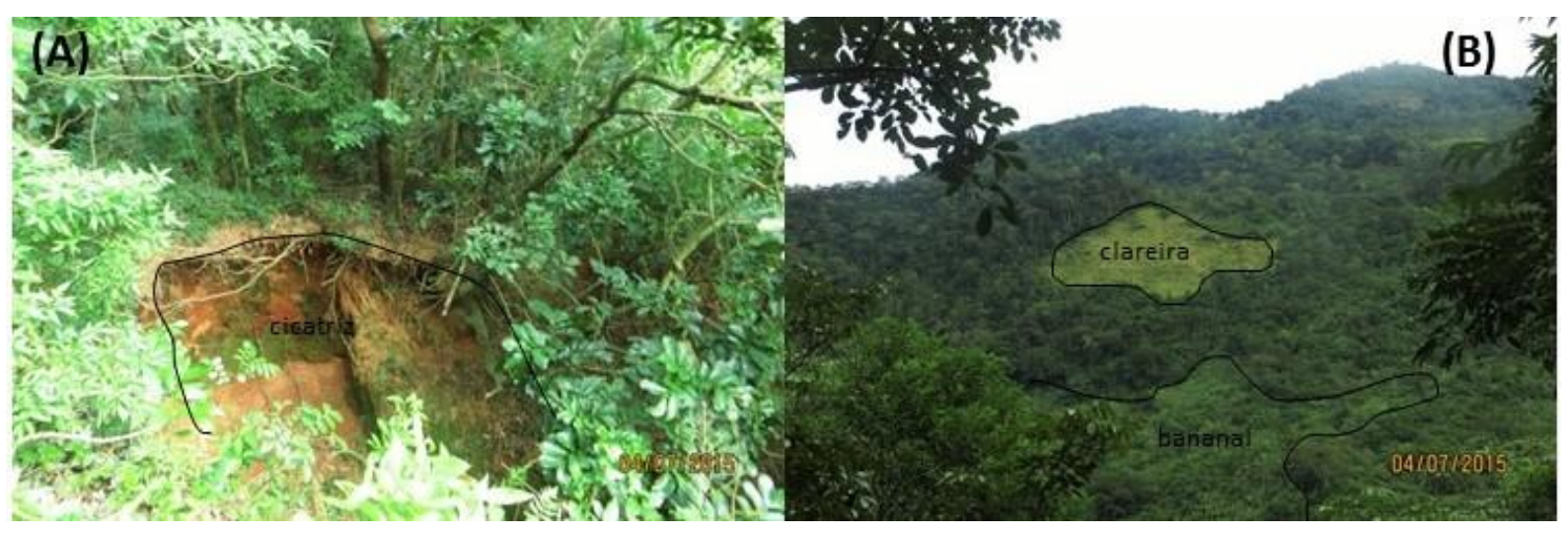

(A) Perda de solos em área de APP; (B) Abertura de clareira para o uso de atividade agropecuária, além de expressa área de bananal na encosta ${ }^{5}$.Fotos: Maria Luciene da Silva Lima.

\footnotetext{
${ }^{5}$ Os bananais em localização de encostas, podem gerar situações de risco favorecendo a movimento e de massa de acordo com a funcionalidade hidrológica de suas raízes. Tese de doutorado: Freitas, Marcelo Motta de -
} 


\begin{tabular}{|c|c|c|}
\hline UFG & 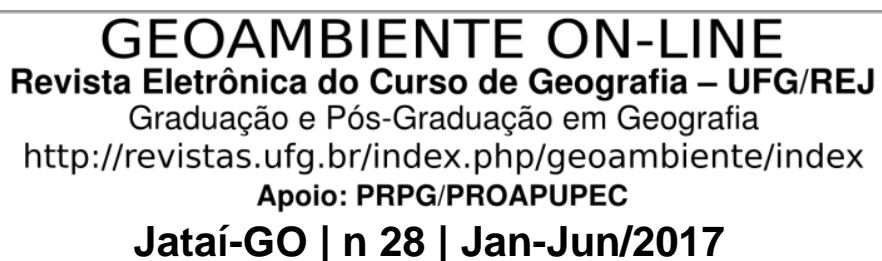 & 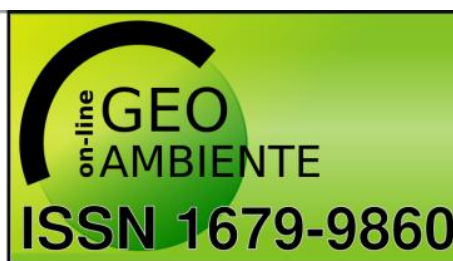 \\
\hline
\end{tabular}

A área do baixo curso da bacia do Sahy, apresenta porções mais significativas no contexto das áreas sensíveis, visto que a combinação das variáveis, sugere uma maior pertinência a processos erosivos, caracterizando essa região da bacia hidrográfica como sensível. Deve-se considerar que essas áreas baixas, compreendem solos pouco desenvolvidos e suscetíveis a processos de inundação. Nessa abrangência há diferentes processos de uso e ocupação, onde a bacia é interceptada pelo eixo rodoviário da BR-101, trecho litorâneo relacionado também com o turismo e veraneios tradicionais, além de crescimento urbano no entorno da rodovia e empreendimentos imobiliários. Processos socioeconômicos que marcam uma nova identidade territorial à região e indicam desafios para melhoria ambiental a partir da organização socioespacial local.

\section{Considerações finais}

- As interações humanas foram se tornando cada vez mais complexas e os processos de ocupação das terras foi acompanhando esse crescimento acelerado. Como consequência, as paisagens vêem sofrendo fortes alterações e um dos problemas da atualidade é a possibilidade de esgotamento dos recursos naturais.

- A avaliação do espaço geográfico consiste em conhecer essas áreas as quais tem sido de aproveitamento de usos múltiplos para a demanda populacional e contrapondo a localização de áreas sensíveis aos processos erosivos. Tal conhecimento, pode subsidiar os estudos das paisagens físicas, ou mesmo buscar esforços metodológicos no apoio a tomada de decisão para melhor planejamento e gestão da bacia hidrográfica como unidade territorial. Em busca de uma proposta de gestão sustentável, vale ressaltar a importância de entender os limites dos sistemas ecológicos e físicos, para que os sistemas sociais, tenham condição de manter interações sustentáveis e não esgotáveis, a partir de ações de manejo adequado, diminuindo riscos a permanência desses sistemas.

- O cenário da área de estudo corresponde a um processo histórico de ocupação territorial contextualizando a paisagem do município a partir das interações do homem com o ambiente ao longo dos últimos séculos, revelando Mangaratiba em suas vulnerabilidades socioecológicas a partir exploração do potencial dos recursos

Funcionalidade hidrológica dos cultivos de banana e territorialidades na paisagem do Parque Municipal de Grumari - Maciço da Pedra Branca - RJ: UFRJ/IGEO, 2003. 
genéticos da região. É importante, e deve-se considerar o importante papel socioambiental do bioma da mata atlântica, o qual propicia importantes serviços ambientais para a população, sendo de extrema importância analisar as áreas de ocupação dos sistemas socioecológicos de modo a identificar quais são as vulnerabilidades que representam esses elementos e jurisdições pertinentes.

- Aqui o objetivo principal foi o de refletir sobre o conceito daquilo que pode ser identificado como área sensível pela literatura científica existente, além da análise do processo histórico de ocupação da área de estudo nos apoiando a entender as espacialidades atuais, e análise integrada representada cartograficamente pelos mapeamentos dos elementos físicos. Esse conhecimento é importante para o planejamento do espaço geográfico, para gerenciamento de contextos vulneráveis e áreas de risco. É difícil impedir ou reverter a intensificação desses fatores que provocam tais mudanças, contudo, nos restas gerenciar os riscos a partir da capacidade de adaptação das dimensões humanas - barreiras sociais e ecológicas - a fim de mitigar os danos e prevenir maiores impactos.

\section{Referências bibliográficas}

BARBOSA, D. R; OLIVEIRA, R. R; SILVA, F. G. Uso do Solo e Ocupação na planície de Inundação do Rio Sahy, Mangaratiba/RJ. IV Workshop Internacional sobre planejamento e desenvolvimento sustentável em bacias hidrográficas. 1824-1834p. 2013.

BONDIM, Miriam. História da cidade de Mangaratiba. - Do arraial Tupiniquim ao cenário de Limite - 1. ed. Rio de Janeiro: Fundação Mário Peixoto, 2014.

BONDIM, Miriam. Resumo da história de ocupação das terras Mangaratibenses. Plano Municipal de Educação - Documento Base. 2015. Disponível em: <http://www.mangaratiba.rj.gov.br/portal/arquivos/informativos/pmm-plano-municipaleducacao-documento-base-2015.pdf> Acesso em 10 jul 2015.

BRASIL. Código Florestal Brasileiro, Lei 12.651/2012. Disponível em <http://www.planalto.gov.br/ccivil_03/_Ato2011-2014/2012/Lei/L12651.htm>. Acesso em 16 jun 2016

CHRISTOFOLETTI, Antônio. Modelagem de Sistemas Ambientais. $1^{\text {a }}$ Ed - São Paulo: Blucher, 1999. 


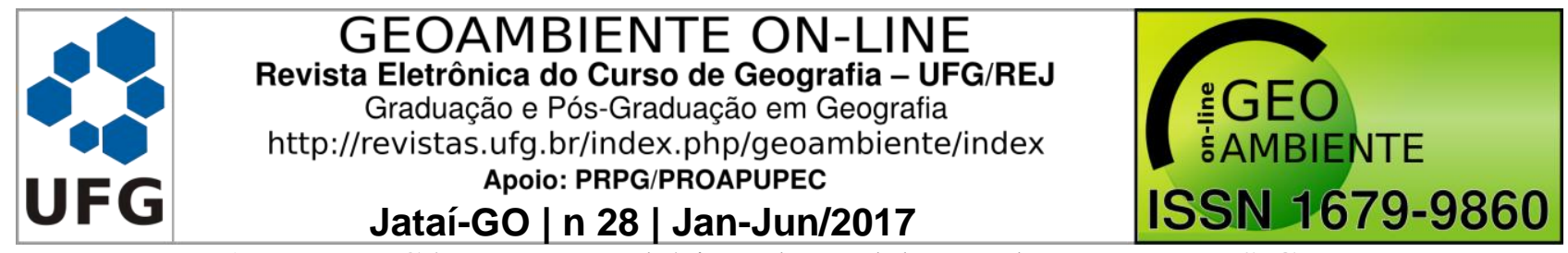

FERREIRA, Marcos César. Funções básicas de modelagem de mapas para SIG. In: Iniciação à análise geoespacial: teoria, técnicas e exemplos para geoprocessamento. - 1.ed. - São Paulo: Editora Unesp, 2014, p. 297-332.

GLASER, Marion. The Social Dimension in Ecosystem Management: Strengths and Weaknesses of Human-Nature Mind Maps. Human Ecology Review, Vol. 13, No. 2, 2006, Society for Human Ecology, p. 122-142. Disponível em: <http://www.humanecologyreview.org/pastissues/her132/glaser.pdf>. Acesso em: 28 mar 2016.

GUIMARÃES, Alberto Passos. O latifúndio cafeeiro. In: Quatro séculos de latifúndio (apresentação de Antônio Houaiss). Ed. - Rio de Janeiro: Paz e Terra, 1989. 255 p. (Estudos brasileiros, v. 24).

JORGE, Maria do Carmo Oliveira; GUERRA, Antonio José Teixeira. Erosão dos solos e movimentos de massa - recuperação de áreas degradadas com técnicas de bioengenharia e prevenção de acidentes. In: Processos erosivos e recuperação de áreas degradadas. - São Paulo: Oficina de textos, 7-28p. 2013.

LEFEBVRE, Henri. A produção do espaço. Trad. Grupo "As (im)possibilidades do urbano na metrópole contemporânea" do Núcleo de Geografia Urbana da UFMG (do original: La production de l'espace. $4^{\mathrm{a} e d}$. Páris: Editions Antrophos, 2000). Primeira versão: início - fev. 2006, cap. I.

MATTOS, Regina Célia de. Mangaratiba: Desafios socioambientais. In: Educação Ambiental: Resgate de valores socioambientais do município de Mangaratiba, RJ. RUA, João, et al; SIQUEIRA, Josafá Carlos de (Org.). - Rio de Janeiro: PETROBRÁS: PUC-Rio, 2003.

MORAES, Antônio Carlos Robert. Geografia: Pequena história Crítica. $21^{\text {a }}$ ed. - São Paulo: Annablume, 152p. 2007.

RUA, João. Mangaratiba e a construção da identidade territorial. In RUA, João, et al. Educação Ambiental: Resgate de valores socioambientais do município de Mangaratiba, RJ. Rio de Janeiro: PETROBRÁS: PUC-Rio, 2003. 


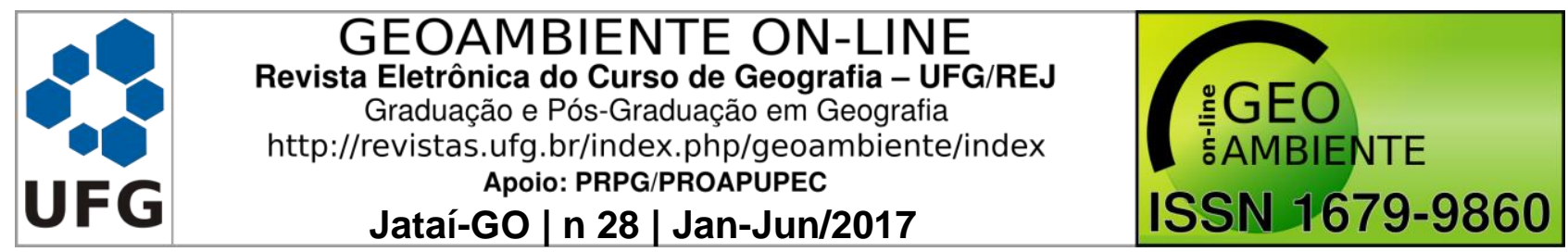

SiBCS - Sistema Brasileiro de Classificação de Solos. Humberto Gonçalvez dos Santos. [et al]. - 3 ed. ver. ampl. - Brasilia, DF: Embrapa, 353 p. 2013.

SOLÓRZANO, Alexandro; RUÍZ, Adi Estela Lazos; OLIVEIRA, Rogério Ribeiro de. Landscape Reading of Urban Forests in Rio de Janeiro: Interpreting Past and Current Socioecological Interactions. Workshop on Landscape Reading Methodologies Guimarães, Portugal, 24-25 September, 2015.

WULF, Andrea. A Invenção da Natureza: a vida e as descobertas de Alexander von Humboldt. Tradução: Renato Marques. - 1.ed. - São Paulo: Planeta, 2016. 